\title{
TERAPIA MEDICAMENTOSA NO DOMICÍLIO: EXPERIÊNCIAS DE MÃES DE CRIANÇAS E ADOLESCENTES COM ANEMIA FALCIFORME
}

\author{
Fernanda Machado Silva-Rodrigues ${ }^{1}$, Natasha S. Sales de Oliveira ${ }^{2}$, Ana Carolina Andrade Biaggi \\ Leite $^{3}$, Michelle Darezzo Rodrigues Nunes ${ }^{4}$, Naiara Barros Polita ${ }^{3}$, Lucila Castanheira Nascimento ${ }^{5}$
}

RESUMO: Objetivo: descrever as experiências de mães de crianças e adolescentes com anemia falciforme acerca da terapia medicamentosa no domicílio. Método: estudo descritivo, com análise qualitativa dos dados, realizado em setembro de 2016. Foram entrevistadas oito mães de crianças e adolescentes, em tratamento para doença falciforme, em Unidade de Internação e Ambulatório de Pediatria de um hospital terciário da capital paulista. Os dados foram organizados, codificados e apresentados em categorias, conforme procedimentos preconizados para análise de conteúdo. Resultados: as mães apresentaram desconhecimento acerca dos cuidados durante a administração dos medicamentos no domicílio, bem como de eventuais efeitos adversos, mecanismo de ação e benefícios das medicações utilizadas. Conclusão: confirmou-se a necessidade da atuação do enfermeiro na orientação das mães para a administração segura e correta dos fármacos no domicílio, a fim de reduzir complicações relacionadas com absorção do medicamento, supressão terapêutica e exposição indevida dos cuidadores à droga.

DESCRITORES: Anemia falciforme; Tratamento farmacológico; Mães; Enfermagem pediátrica.

\section{HOME-BASED MEDICATION THERAPY: EXPERIENCES OF MOTHERS OF CHILDREN AND ADOLESCENTS WITH SICKLE CELL ANEMIA}

ABSTRACT: Objective: describe the experiences of mothers of children and adolescents with sickle cell anemia with regard to home-based medication therapy. Method: descriptive study with qualitative data analysis, developed in September 2016. Eight mothers of children and adolescents under treatment for sickle cell disease were interviewed at the Pediatric Inpatient and Outpatient Service of a tertiary hospital in the state capital of São Paulo. The data were organized, coded and presented in categories, following content analysis procedures. Results: the mothers presented lack of knowledge on care during home-based medication administration, as well as on possible adverse effects, the action mechanism and benefits of the medication used. Conclusion: nurses need to act in advising the mothers for safe and correct drug administration at home, with a view to reducing complications related to the absorption of the drug, therapeutic suppression and caregivers undue exposure to the drug.

DESCRIPTORS: Anemia, Sickle cell; Drug therapy; Mothers; Pediatric nursing.

\section{TERAPIA MEDICAMENTOSA EN DOMICILIO: EXPERIENCIAS DE MADRES DE NIÑOS Y ADOLESCENTES CON ANEMIA DE CÉLULAS FALCIFORMES}

RESUMEN: Objetivo: describir las experiencias de madres de niños y adolescentes con anemia de células falciformes acerca de la terapia medicamentosa en domicilio. Método: estudio descriptivo, con análisis cualitativo de los datos, desarrollado en septiembre del 2016 Fueron entrevistadas ocho madres de niños y adolescentes sometidos a tratamiento para enfermedad de células falciformes en Unidad de Internación y Ambulatorio de Pediatría de un hospital terciario de la capital del estado de São Paulo. Los datos fueron organizados codificados y presentados en categorías, según los procedimientos recomendados para análisis de contenido. Resultados: las madres mostraron desconocimiento acerca de los cuidados durante la administración de los medicamentos en domicilio, y también de eventuales efectos adversos, mecanismo de acción y beneficios de las medicaciones utilizadas. Conclusión: se confirmó la necesidad de actuación del enfermero en la orientación de las madres para la administración segura y correcta de los fármacos en domicilio, con objeto de reducir complicaciones relacionadas a la absorción del medicamento, supresión terapéutica y exposición indebida de los cuidadores a la droga. DESCRIPTORES: Anemia de células falciformes; Tratamiento farmacológico; Madres; Enfermería pediátrica.

'Enfermeira. Doutoranda pelo Programa Interunidades de Doutoramento em Enfermagem da EE/EERP, Universidade de São Paulo (USP). Docente do Curso de Graduação em Enfermagem da Faculdade de Ciências Médicas da Santa Casa de São Paulo (FCMSCSP). São Paulo, SP, Brasil.

${ }^{2}$ Graduanda do Curso de Graduação em Enfermagem da Faculdade de Ciências Médicas da Santa Casa de São Paulo (FCMSCSP). São Paulo, SP, Brasil.

${ }^{3}$ Enfermeira. Doutoranda pelo Programa Interunidades de Doutoramento em Enfermagem da EE/EERP, Universidade de São Paulo (USP). Ribeirão Preto, SP, Brasil.

${ }^{4}$ Enfermeira. Doutora em Enfermagem. Docente do Departamento de Enfermagem Materno-Infantil na Faculdade de Enfermagem da Universidade do Estado do Rio de Janeiro (UERJ). Rio de Janeiro, RJ, Brasil.

${ }^{5}$ Enfermeira. Doutora em Enfermagem. Docente do Departamento de Enfermagem Materno-Infantil e Saúde Pública da Escola de Enfermagem de Ribeirão Preto - USP. 


\section{INTRODUÇÃO}

Os distúrbios onco-hematológicos referem-se a patologias que alteram as funções normais dos elementos presentes no sangue, bem como os fatores responsáveis pela hemostasia. Na infância, esses distúrbios são representados principalmente pelas anemias, leucocitoses e por sangramentos, e ocorrem de forma secundária a infecções, doenças inflamatórias, nutricionais e malignas, sendo as últimas menos frequentes ${ }^{(1)}$.

A Doença Falciforme (DF), grupo de hemoglobinopatias que decorrem da combinação da hemoglobina anômala (S) e outras hemoglobinas alteradas, é uma das doenças hematológicas que mais atinge a população pediátrica(1-2).

A Anemia Falciforme (AF) é a forma mais comum e severa de $\mathrm{DF}^{(2)}$. No Brasil, cerca de 3.500 casos de AF são diagnosticados por ano, o que confere prevalência significativa e importância clínica à doença, tornando-a um problema de saúde pública ${ }^{(3)}$. Esta anemia apresenta elevados índices de morbimortalidade nos continentes Africano e Sul-Asiático, enquanto nos países desenvolvidos a mortalidade tem sido drasticamente reduzida (menos de $2 \%$ até os 15 anos de idade) ${ }^{(4)}$.

Tratamentos específicos para a AF ainda são inexistentes, o que justifica a relevância do diagnóstico precoce para melhorar a sobrevida e a qualidade de vida da criança ${ }^{(2,5)}$. Após a constatação da enfermidade, iniciam-se os protocolos de tratamento estabelecidos por grupos cooperativos nacionais ou internacionais, baseados essencialmente na combinação de diferentes medicamentos de uso contínuo e tratamento de suporte ${ }^{(3)}$. Devido à intensidade do tratamento é importante que ele ocorra em centro especializado no tratamento de doenças hematológicas ${ }^{(4-6)}$.

No Brasil é possível obter o diagnóstico já ao nascimento, mediante a realização do Teste do Pezinho, parte do Programa de Triagem Neonatal do Ministério da Saúde ${ }^{(7)}$. Uma vez identificado que a criança possui DF, será iniciado o controle de sintomas durante toda a sua vida. Os pais serão orientados sobre a importância de manter a hidratação e nutrição do bebê, assim como a necessidade de prevenção de infecções, o que pode ser realizado durante programas de imunizações ou por meio de outras medidas profiláticas $^{(5)}$.

Além de todos esses cuidados, a criança receberá medicações para o controle da doença e dos sintomas mais prevalentes. Entre as opções terapêuticas eficazes há o tratamento com a Hidroxiureia $(\mathrm{HU})$ e o Transplante de Células-Tronco Hematopoiéticas $(\mathrm{TCTH})^{(6-8)}$, sendo esta última a única terapia curativa.

Pacientes e cuidadores podem apresentar dúvidas relacionadas à terapêutica medicamentosa que poderão incidir em problemas como: perda de doses, doses incorretas ou não administração das medicações prescritas, horário incorreto e outras complicações relacionadas à absorção e ao efeito das drogas, além das questões que envolvem a segurança na sua administração(9). Assim, este estudo objetivou descrever as experiências de mães de crianças e adolescentes portadores de AF acerca da terapia medicamentosa no domicílio.

\section{MÉTODO}

Estudo descritivo, com análise qualitativa dos dados, realizado na Unidade de Internação e Ambulatório de Pediatria de um hospital de ensino da capital paulista, referência no tratamento de doenças crônicas na infância. Os pesquisadores convidaram para participar do estudo: mães de crianças e adolescentes em tratamento para AF, em seguimento na instituição e que estivessem recebendo terapia medicamentosa no domicílio. Excluíram-se aquelas que apresentaram limitações para a compreensão do tema e dos objetivos da pesquisa. 
Os participantes foram incluídos após assinatura e esclarecimento das informações contidas no Termo de Consentimento Livre e Esclarecido (TCLE), formalizando sua autorização para participação e subsequente gravação dos dados. Participaram oito mães de crianças e adolescentes em tratamento para AF nos contextos hospitalar e ambulatorial.

Os dados foram coletados por meio de entrevistas semiestruturadas, audiogravadas, realizadas em um único encontro na Unidade de Internação Pediátrica ou no Ambulatório, conforme a disponibilidade das mães, durante o mês de setembro de 2016. A suspensão da inclusão de novos sujeitos ocorreu quando o conjunto de dados empíricos se mostrou suficiente para responder ao objetivo da pesquisa e compreensão do fenômeno estudado(10).

Os processos de análise e coleta dos dados ocorreram concomitantemente, segundo os pressupostos e procedimentos da análise de conteúdo ${ }^{(11)}$. As etapas percorridas foram: 1) Fase de preparação, que consiste na coleta e seleção de dados adequados para a análise de conteúdo; 2) Fase de organização, que inclui a codificação e a criação de categorias, por meio de um processo de abstração; 3) Fase de comunicação, em que os resultados são apresentados em categorias que descrevem o fenômeno estudado $^{(11)}$

Para ilustrar os temas, foram selecionados trechos dos discursos dos sujeitos, os quais foram representados pela letra "E", seguida de um número sequencial, de acordo com a ordem de ingresso na pesquisa.

O estudo foi aprovado pelo Comitê de Ética em Pesquisa da instituição onde os dados foram coletados (Protocolo n. ${ }^{\circ}$ 1.638.459/2016), em respeito aos preceitos éticos adotados em pesquisas com seres humanos ${ }^{(12)}$.

\section{RESUltADOS}

Participaram oito mães de crianças portadoras de AF, com idades entre 24 e 56 anos. A idade das crianças e adolescentes variou de três a 16 anos, e o tempo de diagnóstico da AF de dois a 14 anos, sendo que seis dos casos-índices foram diagnosticados ainda no primeiro ano de vida.

Seis entrevistadas não trabalhavam fora $(75 \%)$ e dedicavam o tempo aos cuidados da criança e do domicílio. Uma das participantes apresentava o ensino superior incompleto e as demais, o ensino médio incompleto.

Após a análise, os dados foram agrupados em duas categorias amplas: Rotina de administração das medicações no domicílio e Aspectos determinantes da observância à terapia medicamentosa no domicílio.

\section{Rotina de administração das medicações no domicílio}

As crianças e adolescentes, cujas mães participaram do estudo, faziam uso de drogas instituídas por protocolos nacionais e internacionais para controle da $\mathrm{AF}$, como o ácido fólico e outras vitaminas do Complexo B, a Hidroxiureia (HU) e Quelantes de Ferro. As mães referiram administrar as medicações diariamente, no mesmo horário, como observado nas falas a seguir:

Bom, o Hidroxiureia dou de manhã, lá para umas nove ou dez horas da manhã, diluído. O Complexo B e o ácido fólico dou à tarde. (E1)

Participantes referiram que seus filhos recebiam as medicações em dias estabelecidos pelo médico, às vezes alternadamente ao longo da semana, especialmente a HU:

Então, o Hidroxiureia, ele [criança] toma duas cápsulas por dia, na segunda e duas na sexta, e os restantes dos dias da semana ele toma uma. (E2) 
Duas participantes mencionaram uma rotina de horário mais flexível na administração das medicações:

Então, a doutora pediu para dar até meio-dia, então não importa o horário que você vai dar, mas até meio-dia. Então, sempre que ele [criança] levanta, eu dou umas oito, nove horas. Eu dou o Hidroxiureia e os outros remédios juntamente. (E2)

Mães referiram administrar a HU à noite, o que se observou decorrer não do conhecimento das recomendações sobre o período em que os efeitos terapêuticos da droga poderiam ser minimizados, mas sim do fato de este horário ser mais conveniente às suas rotinas, uma vez que outras medicações do tratamento já eram habitualmente administradas à noite, tal como observado no depoimento a seguir:

Os horários são sempre iguais, toma sempre à tarde e à noite. Porque ela [criança] vai pra escola de manhã, à noite fica mais sossegado tomar, depois que chega em casa. (E8)

Destacam-se nesta categoria os relatos maternos sobre a administração da HU. Todas as crianças e adolescentes a utilizavam, sendo esta a principal medicação recomendada pelos atuais protocolos terapêuticos para tratamento da AF. Quanto às orientações para administrá-la, as mães afirmaram que foram orientadas somente quanto à posologia, e não especificamente em relação às precauções necessárias para a manipulação da droga, como descrito no trecho abaixo:

Eu dou na seringuinha, coloco $5 \mathrm{ml}$ de água. Eu abro [a cápsula] para misturar com a água e depois dou pra ela. Eu coloco a água num copinho, pego a seringa, puxo a água e vejo se está na quantidade certa, aí jogo o remédio lá dentro e depois coloco na boca dela. (E5)

Somente uma das participantes relatou necessidade do uso de luvas para o preparo do medicamento e correto descarte das sobras. Entretanto, tal informação não foi fornecida com exatidão e nem por um profissional de saúde, mas sim por uma pessoa conhecida:

Tem pessoas que eu conheço que falaram para mim usar luva, até para o bem dela [criança], e se puder usar aquele negócio no rosto [máscara cirúrgica], porque falam que é forte. Falaram para jogar no lixo, não deixar perto de outras crianças que não tomam. (E5)

\section{Aspectos determinantes da observância à terapia medicamentosa no domicílio}

As participantes, de maneira geral, apresentaram conhecimento limitado em relação à doença falciforme, aos cuidados necessários durante o preparo e administração dos medicamentos no domicílio, bem como de seus efeitos adversos. Pode-se identificar esse deficit de informações sobre a doença no discurso a seguir:

O que a doutora me passou é que ia ajudar ela [criança] na Anemia Falciforme. Que se ela tomasse direitinho, ia ajudar bastante. Mas para que cada um [medicamento] serve, não sei, só o "Bezetacil" [Benzetacil@], que serve para não ter inflamação e não ficar gripado, essas coisas, né?(E8)

Duas entrevistadas, quando questionadas sobre as indicações dos medicamentos utilizados pelas crianças, negaram conhecimento sobre as drogas: Não, nem imagino (E2).

Uma delas afirmou, inclusive, não buscar informações a esse respeito: Não, nunca peguei a bula pra ficar lendo. (E1)

Mesmo quando as participantes se mostraram mais instruídas em relação à finalidade das medicações, observaram-se equívocos importantes em seus relatos, como no depoimento a seguir:

Assim, eu acho que o ácido fólico é pra anemia falciforme. O Complexo B, eu acho que é pra imunidade, é vitamina. O Hidroxiureia, que eu já li nas bulas, ele serve para evitar as crises dolorosas e ajuda também na queda da hemoglobina, e é um quelante de ferro, então ajuda a eliminar o ferro. (E6)

Evidenciou-se o desconhecimento das mães quanto aos efeitos terapêuticos e adversos dos medicamentos usuais de seus filhos. Tal fato pode comprometer a terapêutica prescrita no controle da 
doença, principalmente na prevenção de intercorrências comuns na AF, decorrentes dos fenômenos vaso-oclusivos.

Uma das participantes conhecia superficialmente o mecanismo de ação dos fármacos e seus efeitos adversos, por ter participado de uma palestra que abordava este tema em outra instituição hospitalar:

Então, porque eu tive uma palestra lá no hospital, antes dele [criança] começar a tomar (HU). E eu vi os riscos, os favores [benefícios] são maiores o favor do que o risco. Aí eu comecei a dar para ele certinho, do jeito que a médica me explicou. (E6)

Uma das depoentes referiu que o mais difícil no tratamento é lidar com a doença. Segundo ela, se há um "remédio" para tratá-la, seu papel é administrá-lo:

Não, até que não foi difícil [terapia medicamentosa]. Porque difícil é ver eles doentes, então, se o remédio que ajuda, a gente pega o remédio e dá. Porque temos o pensamento de que vai ajudar, que ele vai melhorar e é isso que acontece. (E6)

Observa-se, na fala acima, que a entrevistada demonstrava confiança na medicação e em sua finalidade. Segundo ela, esta poderia ajudar o filho, mesmo desconhecendo que os benefícios terapêuticos podem coexistir com efeitos adversos.

Embora não compreendessem plenamente as finalidades da droga $(\mathrm{HU})$, algumas mães reconheceram seus benefícios e melhora do estado geral das crianças e dos adolescentes:

Aquela Hidroxi de ureia que é mais complicado, não sei para que é, mas sei que ajuda muito ela. (E7)

Depois que eu vi que ela [criança] começou a tomar (HU), ela começou a ficar bem. Eu vendo ela bem, eu fico bem também. (E5)

Uma das mães ressaltou que as vantagens do uso do medicamento se tornaram ainda mais evidentes quando a criança teve a terapia interrompida por falta da medicação no serviço de saúde:

Ajuda realmente, porque esses dias estavam em falta no posto [de saúde]. E ele ficou quase um mês sem tomar. E eles [crianças com AF] não podem ficar sem tomar esse medicamento. (E6)

No início do tratamento, o desconhecimento da doença e do tratamento foram barreiras para a administração das medicações no domicílio, como expresso a seguir:

No começo foi difícil, porque eu não sabia nem o que era isso [doença]. Era muito nova quando eu descobri o que ele [criança] tinha, o meu primeiro filho foi ele. Foi difícil, porque eu não sabia, não tinha noção das coisas. Eu tive que aprender na marra. Hoje eu já me acostumei. (E3)

A falta de esclarecimentos sobre os efeitos das medicações gerou receio e dúvidas quanto à forma correta de administrá-las, conforme expresso no depoimento abaixo:

Foi um pouco difícil [administrar as medicações em casa], porque ver ela [criança] tão "piquinininha" tomando remédio. Porque quando eu fui comprar na farmácia, eu perguntei pra mulher: "Tem Hidroxiureia?" Ela [farmacêutica]: "Tem, é você que vai tomar?", eu falei: "Não, é a minha filha". Ela: "Nossa, tão pequena tomando Hidroxiureia, um remédio tão forte!". Aí que eu fiquei mais assustada. (E5)

\section{DISCUSSÃO}

As duas categorias encontradas demonstraram os equívocos quanto à administração dos medicamentos no domicílio. Em decorrência da falta de orientações, cinco mães referiram administrá-los nos horários mais convenientes para si ou de acordo com a rotina da criança, não necessariamente no horário da prescrição ou no período do dia que minimizasse ou potencializasse os efeitos terapêuticos e/ou adversos dos fármacos. 
As vitaminas do Complexo B e o folato podem ser administrados em conjunto ou separadamente das refeições, a depender da sensibilidade gástrica da criança ou do adolescente. Já a administração da HU deve ser preferencialmente no período noturno, a fim de minimizar o desconforto gástrico, efeito adverso comumente observado ${ }^{(8,13)}$.

Estudo(13) $^{(13)}$ sobre a adesão à HU mostrou que, quanto mais complexos forem os esquemas de administração prescritos, maiores serão as chances de esquecimento das doses, o que é ainda mais provável se os horários variarem durante a semana.

Outro fator importante, presente na literatura e com implicações na adesão a esta medicação, diz respeito à falta de comunicação entre os profissionais e os cuidadores ${ }^{(8)}$. Neste estudo, percebeu-se que a administração das medicações foi incorporada à rotina das participantes e de seus filhos, sem que fossem consideradas as propriedades das drogas em questão.

A HU é um dos medicamentos mais utilizados para minimizar as intercorrências relacionadas à doença falciforme. Trata-se de um quimioterápico cujo mecanismo de ação consiste em aumentar a produção de Hemoglobina Fetal ( $\mathrm{HbF}$ ) e reduzir os estímulos vasoconstritores. Tal fármaco oferece diversos benefícios terapêuticos a crianças e adolescentes com DF, contudo, pode causar sérios efeitos adversos, principalmente decorrentes de seu uso prolongado ${ }^{(5-6)}$.

Estudos $^{(8,13-14)}$ demonstram prevalência de desconforto gastrointestinal, hiperpigmentação da pele, toxicidade renal e hepática. Além desse efeitos, a HU é uma droga mielossupressiva, ou seja, ocasiona diminuição da atividade da medula óssea, por conseguinte, há queda da concentração de glóbulos vermelhos, brancos e plaquetas. Este efeito é terapêutico para a criança que possui a DF, mas não para o cuidador que entra em contato com a droga ${ }^{(13)}$.

Assim, recomenda-se o uso de luvas de procedimento e máscara para evitar o contato da substância com a pele e mucosas, além do correto descarte das sobras do medicamento, que deve ser envolto em um saco plástico e descartado isoladamente em local de difícil acesso para crianças e animais ${ }^{(8,14)}$.

Neste estudo, no entanto, quase a totalidade das cuidadoras não fazia uso de qualquer tipo de equipamento de proteção individual (EPI). Apenas uma entrevistada usava luvas para administrar a droga, porém ela se equivocou ao relatar que as utilizava para o bem da criança e não para sua própria proteção, o que demonstra a escassez de conhecimento e orientações acerca das precauções para a manipulação da HU.

A literatura assinala a necessidade de orientar os pais sobre os efeitos de drogas citotóxicas sobre o organismo das pessoas saudáveis ${ }^{(13)}$. É imperativo que os profissionais de saúde, entre eles o enfermeiro, orientem os cuidadores sobre práticas seguras na manipulação de drogas como a HU, ressaltando seus efeitos deletérios e informando-os sobre alternativas para a manipulação, administração e descarte dessas substâncias no cenário domiciliar ${ }^{(8)}$.

A respeito das limitações observadas nos relatos, quanto à aquisição de informações e à dificuldade de obtenção da principal droga utilizada no tratamento, cabe destacar a relevância do perfil dos cuidadores e sua relação com o maior conhecimento e adesão à terapêutica medicamentosa no domicílio, identificada tanto no presente estudo quanto em outras duas pesquisas internacionais ${ }^{(8,13)}$.

Resultados de outra investigação(15) apontaram que o nível de escolaridade e as características demográficas dos cuidadores primários não influenciaram a adesão ao tratamento. Entretanto, estudo brasileiro ${ }^{(16)}$ mostrou que o perfil demográfico, o nível de escolaridade e os aspectos socioeconômicos exercem influência sobre a complacência com o tratamento. Tal controvérsia na literatura pode decorrer das disparidades socioeconômicas e educacionais dos distintos cenários em que foram desenvolvidos ambos os estudos.

Seis participantes do estudo apresentavam baixo grau de escolaridade e baixa renda. Limitações no grau de instrução podem agravar a compreensão dos efeitos terapêuticos e adversos e questões relativas ao correto descarte das drogas em contexto não hospitalar. 
A questão socioeconômica pareceu ser importante barreira para as boas práticas relacionadas à administração de medicamentos citotóxicos, como a HU, em casa. As precauções necessárias, como a aquisição de EPI para o uso domiciliar, mostraram-se inviáveis para as famílias, se consideradas as dificuldades em adquirir até mesmo as medicações no serviço público de saúde.

A criança portadora de doença falciforme fica hospitalizada cerca de cinco vezes ao ano e necessita de acompanhamento regular com um hematologista ${ }^{(17)}$. Esta patologia crônica requer cuidados vitalícios ${ }^{(18)}$, o que altera a dinâmica familiar e requer adaptação a essa nova realidade. A figura materna, predominante entre as participantes deste estudo, é a que mais sofre consequências relacionadas aos cuidados com a criança, pois abre mão de sua participação na renda familiar para exercer o papel de cuidadora em tempo integral ${ }^{(19)}$.

Nos relatos, foi possível identificar que as cuidadoras tinham uma percepção positiva em relação à terapia medicamentosa, principalmente no que se refere à $\mathrm{HU}$. O desconhecimento parecia tornar a administração do fármaco em domicílio uma atividade corriqueira, de modo que não questionavam eventuais riscos relacionados ao seu uso prolongado. Estudo americano ${ }^{(18)}$ identificou resistência dos cuidadores em relação à terapia com esta droga, em virtude dos seus efeitos deletérios, a saber: alterações gastrointestinais, mielossupressão, erupções cutâneas, potencial teratogênico e carcinogênico.

Devido aos efeitos supracitados, alguns pais se recusaram a administrar a HU para os seus filhos, comprometendo a adesão ao tratamento, diferentemente das cuidadoras entrevistadas neste estudo, que reconheceram mais benefícios do que efeitos prejudiciais das medicações no organismo, possivelmente por desconhecerem e, portanto, não questionarem os fatores negativos da terapia em longo prazo.

$\mathrm{Na}$ ausência ou insuficiência de informações básicas, essas cuidadoras podem cometer erros no momento da administração do medicamento e procurar o serviço de saúde tardiamente, já que desconhecem as propriedades das drogas, bem como os sinais e sintomas sugestivos de que a terapêutica não está evoluindo como o esperado.

Esse desconhecimento denota falhas na orientação realizada pelos profissionais de saúde, com ênfase para o enfermeiro, que mantém maior contato com os cuidadores e desenvolve, como parte de suas atribuições, atividades educativas e informativas ${ }^{(8)}$. Segundo estudo sobre a adesão ao tratamento de pacientes pediátricos com AF, a deficiência na comunicação entre cuidadores e profissionais é um dos fatores que mais propiciam erros relacionados às medicações e à ausência de observância à terapia domiciliar ${ }^{(18)}$.

Uma das entrevistadas relatou ter lido na bula que a HU é um medicamento que ajuda na eliminação do ferro. Entretanto, um dos efeitos adversos da droga é exatamente o oposto, ou seja, retardar a excreção do ferro ${ }^{(13)}$. Tal equívoco demonstra a necessidade de orientação das participantes, pois, mesmo buscando informações por meios próprios, identifica-se dificuldade na interpretação dos conteúdos expressos em bulas ou outras fontes de informação.

Atividades como essa são fundamentais e deveriam ser acessíveis para todos os cuidadores, porém preferencialmente na instituição onde é realizado o acompanhamento, pois, dessa forma, as orientações serão concordantes ao protocolo de tratamento adotado em determinado local, além de seguirem as características da população atendida no serviço.

As informações referentes ao fármaco e seus benefícios têm impacto diretamente proporcional à adesão, ou seja, se o sujeito desconhece a finalidade terapêutica e os aspectos positivos da droga, não a utilizará corretamente ${ }^{(16-18)}$. Em se tratando de medicações como a $\mathrm{HU}$, tal fato está relacionado diretamente aos benefícios da droga, ou seja, se o seu uso for consciente e complacente, menores serão as chances de ocorrerem crises dolorosas e demais complicações relacionadas à $A F^{(15)}$.

Nos aspectos destacados anteriormente, evidencia-se o papel fundamental da educação em saúde, que deve ser desempenhado pelo enfermeiro, tanto durante palestras e dinâmicas quanto por meio de outros recursos instrucionais, sempre de acordo com o nível de compreensão dos familiares. 
Este estudo apresenta duas limitações: ter sido conduzido em apenas uma instituição de saúde e ter abordado somente a perspectiva de mães.

\section{CONCLUSÃO}

Os resultados deste estudo descrevem as experiências de mães de crianças e adolescentes portadores de AF acerca da terapia medicamentosa no domicílio e alertam para o desconhecimento desta clientela a respeito da finalidade das medicações utilizadas durante o tratamento da doença. Revelam também limitações quanto aos cuidados na administração segura das drogas, tais como padronização das doses e rotina de administração, e, sobretudo, no que se refere às precauções relacionadas com a exposição e o descarte da principal droga do protocolo de tratamento (HU).

A terapia medicamentosa no domicílio para crianças e adolescentes portadores de DF é essencial para a continuidade da assistência e melhora do prognóstico. Para tanto, é fundamental que os cuidadores sejam preparados e orientados pelos profissionais para realizarem a correta administração das drogas, minimizando os erros e evitando consequentes riscos à criança e a si mesmos.

Este é um estudo pioneiro na literatura nacional e sugere que pesquisas futuras sejam extensivas a outros sujeitos, como os pais (sexo masculino), adolescentes (que já possuem autonomia para o autocuidado) e profissionais que cuidam desta clientela. Destaca-se a relevância do uso de outras abordagens metodológicas no estudo desta temática e de aspectos correlatos à doença falciforme e ao seu tratamento.

\section{REFERÊNCIAS}

1. Dale JC, Cochran CJ, Roy L, Jernigan E, Buchanan GR. Health-related quality of life in children and adolescents with sickle cell disease. J Pediatr Health Care. [Internet] 2011;25(4) [acesso em 20 mar 2017]. Disponível: https://www.ncbi. nlm.nih.gov/pubmed/21700135.

2. Quinn CT, Rogers ZR, McCavit TL, Buchanan GR. Improved survival of children and adolescents with sickle cell disease. Blood. [Internet] 2010;115(17) [acesso em1 8 mar 2017]. Disponível: http://dx.doi.org/10.1182/blood-2009-07-233700.

3. Gomes LMX, Pereira IA, Torres HC, Caldeira AP, Viana MB. Access and care of individuals with sickle cell anemia in a primary care service. Acta paul.enferm. [Internet] 2014;27(4) [acesso em 10 mar 2017]. Disponível: http://dx.doi. org/10.1590/1982-0194201400058.

4. Ware RE, Montalembert M, Tshilolo L, Abboud MR. Sickle cell disease. The Lancet. [Internet] 2017;390(10091) [acesso em 17 abr 2017]. Disponível: http://dx.doi.org/10.1016/S0140-6736(17)30193-9.

5. Yawna BP, Buchanan GR, Afenyi-Annan AN, Ballas SK, Hassell KL, James AH, et al. Management of sickle cell disease: summary of the 2014 evidence-based report by expert panel members. JAMA. [Internet] 2014;312(10) [acesso em 25 mar 2017].Disponível: http://dx.doi.org/10.1001/jama.2014.10517.

6. Braga JAP. General measures in the treatment of sickle cell disease. RevBrasHematol Hemoter. [Internet] 2007;29(3) [acesso em 22 abr 2017]. Disponível: http://dx.doi.org/10.1590/S1516-84842007000300009.

7. Brasil. Portaria no 822, de 6 de junho de 2001. Programa Nacional de Triagem Neonatal. Diário Oficial da União, 7 junho 2001.

8. Weingart SN, Toro J, Spencer J, Duncombe D, Gross A, Bartel S, et al. Medication errors involving oral chemotherapy. Cancer. [Internet] 2010;116(10) [acesso em 24 mar 2017]. Disponível: http://dx.doi.org/10.1002/cncr.25027. 
9. Rees AL. Hydroxyurea in Pediatric Patients with Sickle Cell Disease:WhatNurses Need to Know. J Pediatr Oncol Nurs. [Internet] 2016;33(5) [acessoem 25 fev 2017]. Disponível: http://dx.doi.org/10.1177/1043454215614962.

10. O'Reilly M, Parker N. "Unsatisfactory saturation": a critical exploration of the notion of saturated sample sizes in qualitative research. Qual. Res. [Internet] 2013;13(2) [acesso em 17 mar 2017]. Disponível: https://doi. org/10.1177/1468794112446106.

11. Elo S, Kyngäs H. The qualitative content analysis process. J AdvNurs. [Internet] 2008;62(1) [acesso em 29 mar 2017]. Disponível: http://dx.doi.org/10.1111/j.1365-2648.2007.04569.x.

12. Ministério da Saúde (BR). Conselho Nacional de Saúde. Diretrizes e normas regulamentadoras de pesquisa envolvendo seres humanos. Resolução n. 466, de 12 de Dezembro de 2012. Brasília; 2012.

13. Badawy SM, Thompson AA, Penedo FJ, Lai JS, Rychlik K, Liem RI. Barriers to hydroxyurea adherence and health-related quality of life in adolescents and young adults with sickle cell disease. Eur J Haematol. [Internet] 2017;98(6) [acesso em 23 mar 2017]. Disponível: http://dx.doi.org/10.1111/ejh.12878.

14. Walsh KE, Cutrona SL, Kavanagh PL, CrosbyaLE, Malone C, LobnerK, et al. Medication adherence among pediatric patients with sickle cell disease: a systematic review. Pediatrics. [Internet] 2014;134(6) [acesso em 29 mar 2017]. Disponível: http://dx.doi.org/10.1542/peds.2014-0177.

15. Green SN, Barrala S. Emerging science of hydroxyurea therapy for pediatric sickle cell disease. PediatrRes. [Internet] 2014;75(1-2) [acesso em 28 abr 2017]. Disponível: http://dx.doi.org/10.1038/pr.2013.227.

16. de Gusmão JL, Mion Júnior D. Adherence to the treatment - concepts. Rev bras hipertens. [Internet] 2006;13(1) [acessoem30abr2017].Disponível: http://departamentos.cardiol.br/dha/revista/13-1/06-adesao-ao-tratamento.pdf.

17. Al-Anazi KA. Hydroxyurea Therapy in Patients with Sickle Cell Disease. Transl Med. [Internet] 2015;(5) [acesso em 12 mai 2017]. Disponível: http://dx.doi.org/10.4172/2161-1025.1000145.

18. Heeney MM, Ware RE. Hydroxyurea for children with sickle cell disease. PediatrClin North Am. [Internet] 2010;24(1) [acesso em 06 mai 2017]. Disponível: http://doi.org/10.1016/j.hoc.2009.11.002.

19. Guimarães TMR, Miranda WL, Tavares MMF. The day-to-day life of families with children and adolescents with sickle cell anemia. Rev. Bras. Hematol. Hemoter. [Internet] 2009;31(1) [acesso em 30 abr 2017]. Disponível: http:// dx.doi.org/10.1590/S1516-84842009005000002. 